\title{
Regime tecnológico e emergência dos padrões de estratégias inovativas das firmas
}

\author{
Evaldo Henrique da Silva \\ Universidade Federal de Viçosa, Viçosa (MG), Brasil \\ Lia Hasenclever \\ Universidade Federal do Rio de Janeiro, Rio de Janeiro (RJ), Brasil
}

Recebido: 22/01/2012 Versão Revisada (entregue): 21/06/2012 Aprovado: 10/09/2012

\section{Resumo}

Neste trabalho é apresentado um modelo de simulação para analisar os nexos de causalidade entre as características do regime tecnológico e a emergência de padrōes industriais de estratégia inovativa das firmas. Em função de algumas particularidades do modelo, a exemplo do pressuposto de racionalidade extremamente limitada e da relação cumulativa-estocástica entre capacidade absortiva e sucesso inovativo das empresas, este trabalho permite novas reflexões para o estudo da dinâmica tecnológica e industrial. A primeira delas é que a emergência dos padrões de estratégia tecnológica é condicionada não somente pelas características do regime tecnológico, mas também pelas condições iniciais da simulação, indicando que o contexto histórico é igualmente importante para determinação desses padrões. Outra conclusão relevante diz respeito ao tempo necessário para a emergência desses padrões, o qual pode ser relativamente longo, pois é influenciado pelas características da dinâmica seletiva e pelo tempo necessário para que as empresas reavaliem suas estratégias inovativas.

PALAVRAS-CHAVE | Inovação; Competitividade; Simulação; Dinâmica Industrial

Código JEL | O33 


\title{
Technological Regime and Emergency of Patterns of Innovative Strategies of Firms
}

\begin{abstract}
This paper presents a simulation model to analyze the causal links between these characteristics and the emergence of innovative strategy of industrial firms. Due to some peculiarities of the model, such as the presupposition of extremely limited rationality and the relationship between cumulative-stochastic absorptive capacity and innovative success of firms, this paper permit new ideas for the study of technological and industrial dynamics. The first is that the emergence of patterns of technology strategy is conditioned not only by the technological features of the system, but also by the initial conditions of the simulation, indicating that the historical context is also crucial for determining these standards. Another important conclusion concerns the time required for the emergence of these patterns, which can be relatively long as it is influenced by the characteristics of selective dynamics and the time required for the innovative firm to reassess their innovative strategies.
\end{abstract}

KeYwords | Innovation; Competitiveness; Simulation; Industrial Dynamics

JEL-CODE | O33

\section{Introdução}

Em quase todas as vertentes teóricas das ciências econômicas é aceito o postulado de que as decisões dos agentes econômicos são condicionadas por imperativos de natureza econômica, entendidos como força criadora dos padrões de conduta que os economistas usam na formulação de modelos teóricos e empíricos.

A hipótese de maximização dos lucros, por exemplo, tem por referência a premissa dos rendimentos decrescentes. Por outro lado, a existência de economias de escala é o alicerce do poder de mercado e das estratégias de mark up das empresas 
oligopolistas. Na economia evolucionária existe o postulado de que a conduta dos agentes econômicos é regulada por imperativos de natureza tecnológica, que fazem brotar os padrões de estratégias inovativas e competitivas das firmas.

A decifração dos nexos de causalidade entre esses imperativos e a emergência de padrões de estratégias inovativas envolve algumas noções teóricas radicalmente diferentes daquelas que compõem o arcabouço teórico dos modelos de dinâmica econômica da corrente mainstream. Uma delas é a noção de emergência, expressa na expectativa de que o sistema manifeste propriedades dinâmicas e evolutivas impossíveis de serem deduzidas a partir das propriedades dinâmicas e evolutivas das partes desse sistema.

Há mais de uma década, número crescente de autores pertencentes à corrente mainstream tem reconhecido a seriedade das críticas que apontam falhas nos modelos de equilíbrio sistêmico, derivado do postulado do agente maximizador (AZARIADIS, 1998; BENHABIB, 1992; BROCK; MALLIARIS, 1989)

Por conta desse revisionismo, as noçôes de caos e de multiequilíbrio estão sendo incorporadas na modelagem micro e macroeconômica no campo das teorias mainstream. Vale ressaltar que tais noções não contradizem o pressuposto do agente maximizador, indicando que a hipótese do agente bem informado não é condição suficiente para o equilíbrio dinâmico assintoticamente ótimo (SHONE, 2002), o qual, entretanto, pode ser alcançado se a trajetória temporal de pelo menos uma variável do sistema for passível de controle (SHONE, 2002). O equilíbrio dinâmico torna-se resultado plausível em decorrência da hipótese do agente controlador: um agente capaz de interferir nas decisões dos agentes individuais para gerar trajetórias típicas de soluções ótimas.

A noção de emergência ou de auto-organização, que norteia os modelos evolucionários de dinâmica tecnológica e industrial, não se confunde com a noção de caos ou de multiequilíbrio.

Modelos de simulação com propriedade auto-organizativa deverão produzir trajetórias temporais com padrōes bem definidos, ou seja, trajetórias com tendências previsíveis, porém impossíveis de serem deduzidas ou intuídas antes da simulação. Nesses modelos não existem determinaçôes derivadas da hipótese de que os agentes tomam decisões guiados por funções de otimização. O que prevalece são regras práticas de decisão, condizentes com a hipótese de que os agentes aprendem por meio de tentativas e erros. Nesse caso, vale o pressuposto de que os agentes reconhecem a imprevisibilidade do sistema e suas limitações cognitivas em termos de entendimento do funcionamento desse sistema. Não obstante, ainda que os agentes sejam 
racionalmente limitados (SIMON, 1979), o sistema pode produzir trajetórias bem definidas sem a intervenção regulatória.

Entender os nexos de causalidade entre os imperativos tecnológicos e a dinâmica auto-organizativa é o principal desafio da modelagem evolucionária. De que modo o sistema produz a auto-organização sem as funções otimizadoras e sem o agente controlador?

A formulação dos conceitos de paradigmas tecnológicos, trajetória tecnológica e regime tecnológico foi de crucial importância para a investigação dessa questão. Mas, apesar de todo o esforço acumulado, a economia evolucionária demanda pesquisas mais exaustivas das relações de causalidade entre a natureza do processo gerador dos conhecimentos tecnológicos - isto é, do processo ou regime de aprendizagem tecnológica - e a emergência de padrôes de mudança tecnológica (adoção, seleção e difusão de novas tecnologias) ou a convergência das estratégias inovativas entre as empresas que integram uma determinada indústria.

Este artigo representa uma tentativa de unir duas contribuiçóes seminais ${ }^{1}$ que investigam as relações de causalidade entre os imperativos tecnológicos (regime tecnológico) e as estratégias inovativas das empresas, na crença de que essa junção possa eliminar lacunas importantes deixadas por essas contribuiçōes. $\mathrm{O}$ fio condutor dessa síntese reside na concepção evolucionária de tecnologia: um conjunto de peças do conhecimento (conhecimento teórico, conhecimento tácito, know how, tentativas e erros, etc.), cuja aplicação é circundada de incertezas técnicas e econômicas. Obviamente, essa definição é a base do entendimento da dinâmica tecnológica da qual emergem os padrões de estratégias inovativas.

A firma é uma unidade orgânica criada para explorar as potencialidades de mercado que a tecnologia faz nascer, mas num invólucro de incertezas. Isso significa que a modelagem da dinâmica tecnológica tem como unidade essencial a empresa não representativa, da qual emanam decisões cujos resultados representam eventos futuros que, na sua maioria, carregam alto grau de incerteza.

A heterogeneidade das unidades de análise (as firmas), a interatividade entre essas unidades, o ambiente de incerteza e a ocorrência de não linearidades nas relações de causalidade são aspectos que apontam para a necessidade do uso de modelos de simulação.

Neste artigo é apresentado um modelo de simulação da dinâmica tecnológica de uma indústria hipotética, formada por um conjunto de empresas que competem no desenvolvimento e aperfeiçoamento de uma nova tecnologia. As equações desse

1 São elas: Cohen e Levinthal (1989) e Silverberg e Verspagen (1994). 
modelo e os valores dos seus parâmetros foram definidos exclusivamente a partir de inferências teóricas. Não houve a intenção de simular uma dinâmica real. O propósito foi investigar teoricamente a relação ou os nexos de causalidade entre o regime tecnológico e a convergência das estratégias inovativas, em um conjunto de firmas que interagem entre si produzindo produtos idênticos e que estão empenhadas em um esforço tecnológico de criação de vantagens competitivas.

Para esse propósito, foram criados dois cenários. Em um deles, a nova tecnologia tem como uma de suas características o alto grau de complexidade do conhecimento. No outro, o conhecimento é menos complexo. As mudanças em outras características do regime tecnológico (tacitividade, cumulatividade e apropriabilidade) não foram encenadas, o que pode ser feito em estudos posteriores. Essa ênfase na complexidade do conhecimento foi motivada pela hipótese de que a capacidade das firmas de absorver conhecimentos gerados externamente (empresas rivais, instituições tecnológica, etc.) é diretamente condicionada pelo grau de complexidade desses conhecimentos.

As principais conclusóes extraídas das rodadas de simulação foram:

- os imperativos tecnológicos ou regimes de aprendizagem tecnológica condicionam as estratégias inovativas das firmas, criando padróes de mudança tecnológica;

- entretanto, a emergência desses padrões é processo lento e oneroso (associado à perda de market share para muitas empresas);

- o regime tecnológico que envolve conhecimento complexo faz emergir uma indústria intensiva em $\mathrm{P} \& \mathrm{D}$;

- os eventos iniciais, a exemplo das estratégias inovativas de cada uma das firmas e da realização de sucesso inovativo, compõem o conjunto de fatores que delineiam o caminho temporal das variáveis analisadas;

- em alguns casos, esses eventos podem inverter as tendências dominantes, fazendo emergir uma indústria de baixa intensidade de P\&D em um contexto de alto grau de complexidade do conhecimento, ou vice-versa.

\section{Referências teóricas}

A elaboração do conceito de paradigma tecnológico (DOSI, 1982, 1988) foi decisiva para compreensão do papel dos imperativos tecnológicos sobre as estratégias inovativas e competitivas das firmas. $\mathrm{Na}$ formulação desse conceito ficou clara a natureza coevolutiva (dinâmica e complexa) das relações de determinação entre o paradigma tecnológico e as estratégias das firmas que exploram as oportunidades 
tecnológicas geradas pelo paradigma tecnológico ${ }^{2}$. Isso porque, no momento em que emerge um novo paradigma tecnológico, são ativados mecanismos de seleção das inovações, das estratégias e das próprias firmas, cujas variáveis-chave e resultados serão conhecidos somente a posteriori. Desse modo, a emergência do padrão de conduta das empresas, relativo às suas estratégias inovativas e competitivas, deve ser entendida como um processo de longo prazo, o qual é movido por determinações cujas variáveis e interações não podem ser conhecidas e preditas pelas firmas ex ante. A própria noção de padrão de conduta não pode ser confundida com a noção de firma representativa, visto que esses mecanismos promotores da convergência das estratégias das empresas comportam uma dinâmica complexa que pode preservar a heterogeneidade ou a diversidade entre as firmas até o momento em que o paradigma tecnológico chega ao fim e as empresas entram em extinção.

O postulado fundamental dos modelos evolucionários de dinâmica industrial reside na tese de que os paradigmas tecnológicos carregam as sementes de onde brotam os imperativos tecnológicos, que irão balizar o processo evolutivo das estratégias das firmas e das estruturas de mercado. Essas sementes são identificadas nas características do regime de aprendizagem tecnológica, ou simplesmente regime tecnológico (MALERBA; ORSENIGO, 1993, 1997), cujas características são marcas exclusivas de cada paradigma tecnológico.

Segundo Dosi (1988, p. 1.127), o paradigma tecnológico é definido como:

A "technological paradigm" defines contextually the needs that are meant to be fulfilled, the scientific principles utilized for the task, the material technology to be used, the material technology to be used. In other words, a technological paradigm cam be defined as a "pattern" of solution of selected technoeconomic problems based on highly selected principles derived from the natural sciences [...] A technological paradigm is both an - exemplar - an artifact that is to be developed and improved (such as a car, an integrated circuit, a lathe, each with its particular technoeconomic characteristics) - and a set of heuristics (e.g., Where do we go from here? Where should we search? What sort of knowledge should $w$ draw on?

Por sua vez, trajetória tecnológica é entendida como: "the activity of technological process along the economic and technological trade-offs defined by a paradigm" (DOSI, 1988, p. 1.128).

2 A identificação das firmas que exploram o mesmo paradigma tecnológico é fundamental para delimitação do conjunto daquelas que disputam o mesmo mercado, isto é, do conjunto de firmas rivais. Neste artigo, a definição de mercado ou de firmas rivais é parte integrante do conceito de trajetória tecnológica, que será definido logo adiante. 
É plausível supor que as características tecnológicas do artefato que inaugura o novo paradigma tecnológico definem o grau de oportunidade tecnológica, de complexidade, de cumulatividade e de apropriabilidade dos conhecimentos materializados no desenvolvimento e aperfeiçoamento desse artefato. Em outros termos, o paradigma tecnológico, desde o seu nascimento, define os imperativos tecnológicos, cuja análise tem como referência teórica o conceito de regime tecnológico.

O princípio de que os imperativos tecnológicos delineiam a evolução industrial é a marca principal da modelagem evolucionária (NELSON; WINTER, 1982; WINTER, 1984; SILVERBERG et al., 1988; CHIAROMONTE; DOSI, 1993; MARSILI et al., 1995), havendo diversos estudos de naturezas teórica e empírica dedicados à análise do papel do regime tecnológico na determinação das estratégias inovativas e competitivas das firmas (PAVITT, 1984; BELL; PAVITT, 1993; KLEVORICK et al., 1995; MARSILI; VERSPAGEN, 2001).

Quanto à análise dos nexos de causalidade entre as características do regime tecnológico (oportunidade tecnológica, complexidade, etc.) e a emergência dos padrões de estratégias inovativas e de mudança tecnológica, é necessário enfatizar que esses padrões constituem uma propriedade emergente; quer dizer, uma propriedade inesperada do ponto de vista dos padrōes de conduta e de adoção de novas tecnologias no âmbito de cada firma.

É trivial o fato de as empresas estarem empenhadas na criação de vantagens competitivas individuais. A diferenciação é um fenômeno inerente à concorrência. Por isso, a emergência de padrões de conduta que promovem a convergência das estratégias inovativas é algo inesperado, visto que a concorrência se materializa no esforço de diferenciação.

Se no âmbito individual as firmas estão buscando estratégias de diferenciação, por que no âmbito global (do conjunto das empresas) emerge uma tendência de convergência dessas estratégias?

Obviamente, a resposta não é trivial. $\mathrm{Na}$ verdade, poucos autores evolucionários dedicaram esforços na investigação dessa questão. No geral, o pressuposto de que o regime tecnológico faz brotar os padrões de estratégia é adotado com apoio de estudos empíricos.

Há autores evolucionários que adotam uma perspectiva contrária ao admitirem a proeminência da heterogeneidade interfirmas. A diversidade intraindústria é considerada tão profunda que as características individuais de cada firma despontam como variável-chave para explicar a dinâmica tecnológica e industrial. Nesse tipo de abordagem não é incluído o papel dos imperativos tecnológicos. $\mathrm{O}$ foco principal 
dessa linha de pesquisa recai sobre os aspectos referentes à estrutura de mercado e, crucialmente, sobre as variáveis próprias do âmbito da firma (KUPFER; ROCHA, 2005). Por conta de tais características, o desenvolvimento dessa linha de pesquisa é fortemente dependente de surveys ou banco de microdados de empresas individuais.

Numa vertente mais teórica, vale citar o trabalho de Vieira Filho e Silveira (2011), que possui alguma afinidade com o presente estudo. Os autores desenvolvem um modelo de simulação adotando as mesmas referências teóricas deste artigo. Não obstante, apesar de adotarem o conceito de regime tecnológico, os autores não exploram a noção de emergência ou de auto-organização; ao contrário, exploram a noção de diversidade para estudar a dinâmica tecnológica no setor agrícola. Com isso, o modelo de simulação proposto por esses autores não produz o fenômeno de convergência das estratégias inovativas das firmas.

A existência ou não de padrōes de estratégias inovativas e de padrões de mudança tecnológica em cada setor é uma questão puramente empírica. No presente artigo é admitida, a priori, a ocorrência desses padrōes, senão em todos pelo menos na maior parte dos setores.

O propósito deste artigo é preencher uma lacuna de natureza teórica. A adoção de modelos de simulação para investigar os nexos de causalidade entre o regime tecnológico e a dinâmica auto-organizativa, que efetivamente faz brotar esses padrões, é um campo de pesquisa pouco explorado.

No momento, podem ser apontadas duas contribuições seminais: Cohen e Levinthal (1989) e Silverberg e Verspagen (1994). O modelo de simulação apresentado neste artigo é resultante de uma síntese entre essas duas contribuições, motivada pela observação de que existem pontos de complementaridades entre elas, apesar de suas diferenças.

Uma diferença básica está no fato de a primeira adotar o pressuposto de que as empresas têm pleno conhecimento dos ganhos e perdas (payoffs) de todas as combinações possíveis que definem a função de reação das firmas rivais, ${ }^{3}$ Quer dizer, a escolha das estratégias inovativas das firmas é regida pelo princípio da racionalidade substantiva, ${ }^{4}$ o que é uma falha séria do ponto de vista da economia evolucionária. Apesar dessa falha, o estudo enfatiza os efeitos das mudanças nas características do regime tecnológico sobre as estratégias inovativas das firmas (nesse caso, a inten-

3 A concepção de firmas rivais é a mesma encontrada nos livros da microeconomia tradicional.

4 Ver Dosi e Egidi (1991) e Crocco (1999) para definições de racionalidade substantiva. 
sidade de gastos com P\&D), o que não se observa na contribuição de Silverberg e Verspeagen (1994). Estes autores demonstram que o mecanismo de aprendizagem por tentativas e erros na escolha da estratégia inovativa das firmas produz, no longo prazo, a emergência de padrões de estratégias inovativas entre essas empresas, mas não analisam os efeitos de mudanças no regime tecnológico sobre esses padrões.

O modelo apresentado neste artigo é produto do esforço de integração dessas duas contribuições. São aproveitados o conceito de capacidade absortiva proposto por Cohen e Levinthal (1989) e a sugestão de Silverberg e Verspagen (1994) de que essa capacidade impacta diretamente a probabilidade de inovar, e não os lucros das firmas, conforme sugerem Cohen e Levinthal (1989).

A peça principal dessa integração tem como síntese as seguintes equações:

$$
\pi_{i}=M_{i}+\gamma_{i}\left(\theta \sum_{j}^{n-1} M_{j}+T\right)
$$

$\gamma_{i}=\phi\left(M_{i}, \beta\right)$

sendo: $\pi_{\mathrm{i}}=$ probabilidade de sucesso da atividade inovativa (o subscrito $i$ é o identificador da firma); $M_{i}=$ gastos com P\&D; $\gamma_{i}=$ índice da capacidade absortiva dos conhecimentos externos (varia de zero a um); $\theta=$ grau de spillover (varia de zero a um); $M_{j}$ = gastos com P\&D das firmas rivais; $T$ = grau de oportunidade tecnológico (tem como proxy os gastos do governo e das firmas não rivais e de outras instituiçóes em C\&T e/ou P\&D); $\beta=$ grau de complexidade da base de conhecimento (tem como variável proxy o número de áreas do conhecimento e o nível de qualificação da equipe envolvida na atividade inovativa).

No modelo de Cohen e Levinthal (1989), a variável dependente $\pi_{\mathrm{i}}$ da primeira equação representa o acréscimo no estoque de conhecimento da firma $i$, o qual reflete diretamente nos lucros da empresa. No modelo de Silverberg e Verspagen (1994), é adotada uma versão linear das equações (1) e (2), sendo a variável dependente uma função de distribuição de probabilidade do tipo Poisson, relativa ao sucesso do esforço inovativo (variável $\pi_{\mathrm{i}}$ ). ${ }^{5}$

O efeito do grau de complexidade da base de conhecimento (parâmetro $\beta$ ) sobre a capacidade absortiva da firma pode ser analisado com base no Gráfico 1.

5 É adotada nesse modelo a hipótese de safras tecnológicas do estoque de capital. O número de atualizações tecnológicas de cada unidade de capital é regido por essa distribuição de Poisson. 
GRÁFICO 1

Efeito do grau de complexidade da base de conhecimento sobre a capacidade absortiva da firma

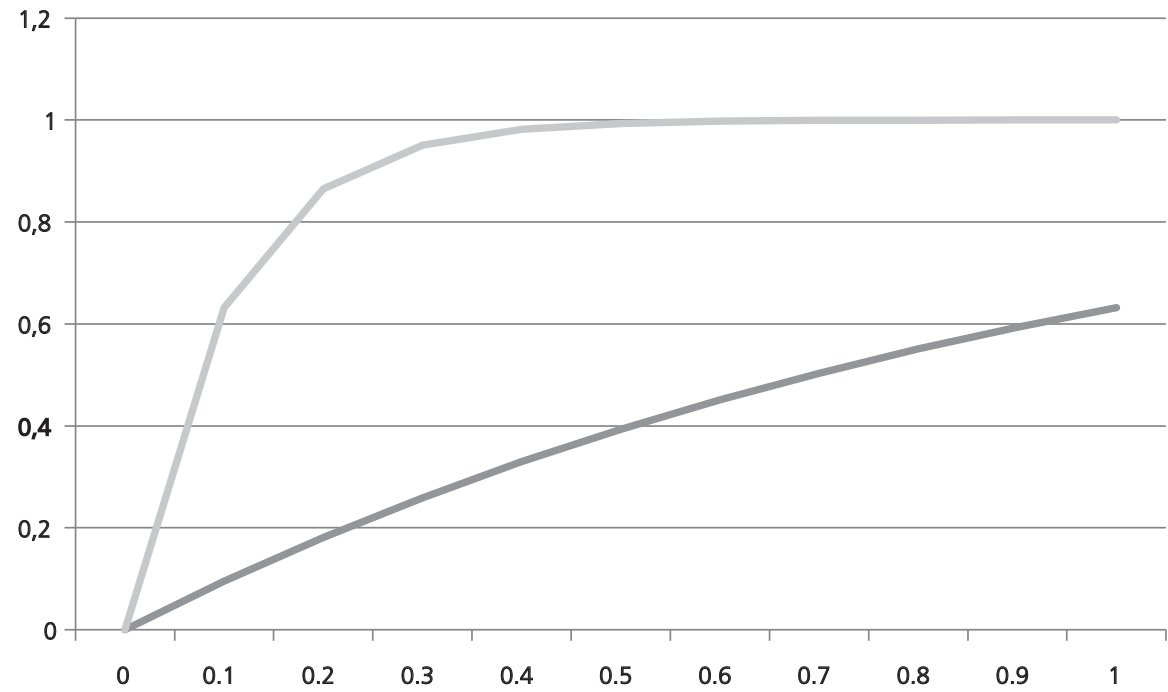

Fonte: Elaboração dos autores.

As curvas $B=10$ e $B=1$ foram extraídas da função $y_{i}=1-\exp \left(-B M_{i}\right)$. No primeiro caso, a capacidade absortiva alcança patamares próximos da unidade em níveis relativamente baixos de $b$ (nesse caso, $b$ representa os gastos com P\&D em proporção das vendas). Assim, paradigmas tecnológicos cuja base de conhecimento apresenta baixo grau de complexidade (parâmetro $\beta$ com alto valor), associados a elevado grau de spillover (parâmetro $\theta$ com alto valor) e de oportunidade tecnológica (parâmetro $T$ com alto valor), irão gerar trajetórias tecnológicas caracterizadas pela baixa intensidade de gastos com P\&D, em razão da disponibilidade e da facilidade de absorção de conhecimentos externos por parte das firmas. Por outro lado, maior intensidade de P\&D é compartilhada com maior grau de complexidade da base de conhecimento e de oportunidade tecnológica, associada ao maior grau de spillover. Nesse caso, o aumento da intensidade de gastos com P\&D responde à necessidade das firmas de aumentar sua capacidade absortiva em um contexto de amplas possibilidades de sucesso inovativo, trazidas pelo conhecimento externo.

Cohen e Levinthal (1989) desenvolveram um modelo teórico com o qual analisam exaustivamente as relações de causalidade entre o valor desses parâmetros e os gastos com P\&D das firmas - tudo enriquecido com pesquisa empírica. Não 
obstante, a dinâmica do modelo segue a lógica da teoria dos jogos, carregando a noção de equilíbrio por conta da hipótese de que as firmas têm conhecimento da sua matriz de payoffs para o conjunto de estratégias inovativas de todas as empresas. O equilíbrio gerado pelo modelo é do tipo Nash-simétrico, ${ }^{6}$

Silverberg e Verspagen (1994) incorporam em seu modelo uma equação de aprendizagem para as estratégias inovativas das firmas, isto é, dos seus gastos com $P \& D$. Essa equação é peça-chave para se obter a convergência da intensidade dos gastos com $\mathrm{P} \& \mathrm{D}$ das firmas rivais e, por conseguinte, fazer emergir o padrão de estratégia inovativa dentro do conjunto de empresas. Segundo os autores, a taxa de crescimento das vendas das firmas rivais é, ao lado do acaso, o determinante da probabilidade de mudança da estratégia de cada empresa.

Além de não contemplarem os efeitos das mudanças do regime tecnológico sobre os gastos com P\&D das firmas, as séries temporais geradas pelo modelo de simulação de Silverberg e Verspagen (1994) abarcam um período de tempo pouco condizente com a realidade. A convergência ${ }^{7}$ emerge a partir de períodos superiores a 3.000 observações, insinuando uma vida milenar das firmas ou que elas mudam suas estratégias em período de tempo muito curto (por exemplo, diariamente).

Deixando de lado suas falhas, o modelo de Silverberg e Verspagen (1994) gera resultados em favor da tese de que o regime tecnológico condiciona as interaçóes competitivas no sentido de produzir a emergência dos padrôes de estratégia tecnológica em um ambiente de incerteza forte ou substantiva. ${ }^{8}$ Essa é, efetivamente, a conclusão que melhor se adequa aos preceitos da economia evolucionária. No entanto, resta resolver a questão do tempo necessário para consolidação desses padrōes (no modelo, foram necessárias mais de 3.000 observações) e analisar os efeitos das mudanças de regime tecnológico sobre as propriedades emergentes desse modelo.

6 Os formatos e os parâmetros das equações do modelo foram definidos de modo a produzir o equilíbrio Nash-simétrico. Nesse caso, a simetria é uma simplificação do modelo. A hipótese fundamental é a dos rendimentos decrescentes dos investimentos em P\&D.

7 Os autores empregam o conceito de "atrator", chamando atenção para o fato de o modelo produzir trajetórias relativamente estáveis no longo prazo, apesar de operar com um sistema de equações de solução indeterminada, ou seja, um sistema sem solução de equilíbrio. Vale lembrar que esse atrator é, por definição, não caótico, não sendo, portanto, um atrator "estranho". A existência do atrator, por sua vez, indica que a tendência de convergência das estratégias inovativas é compartilhada com determinado grau de diversidade dessas estratégias.

8 Incerteza do tipo keynesiana, que se manifesta no contexto em que os agentes econômicos não conhecem a distribuição de probabilidade dos eventos futuros relevantes - para mais detalhes, ver Dosi e Egidi (1991) e Crocco (1999). 


\section{Linhas básicas do modelo}

A base de construção do modelo é puramente teórica, fortemente inspirada em algumas contribuições de autores evolucionários, em especial os trabalhos de Cohen e Levinthal (1982) e Silverbeg e Verspagen (1994). O objetivo é investigar no plano teórico os nexos de causalidade entre os condicionantes do processo de aprendizagem tecnológica, isto é, as características do regime tecnológico, e a emergência de padrōes de estratégia invotivas em uma indústria hipotética.

Por essa razão, as equações do modelo estão todas elas embasadas em suposições teóricas. $\mathrm{O}$ mesmo ocorre com a definição dos valores dos parâmetros dessas equaçōes. A maior parte dessas suposiçóes foi produzida a partir de uma tentativa de síntese entre as contribuições teóricas de Cohen e Levinthal (1982) e de Silverberg e Verspagen (1984). Esse esforço de síntese nasceu da observação de que os pressupostos de ambos os estudos podem ser compartilhados, gerando assim um modelo teórico mais consistente para análise do papel do regime tecnológico na determinação de uma dinâmica auto-organizativa.

O pressuposto da racionalidade substantiva9 é requisito fundamental para se obter a solução analítica do modelo de Cohen e Levinthal (1989). No modelo de Silverberg e Verspagen (1994), os payoffs das estratégias inovativas são conhecidos somente ex-post, isto é, o impacto de cada conjunto de estratégias poderá ser avaliado somente após a implementação dessas estratégias. $\mathrm{O}$ único parâmetro do processo de aprendizagem nesse modelo reside na capacidade das empresas de observarem o desempenho das vendas das firmas rivais, delineando assim o cenário de probabilidade não casuístico de mudança das estratégias inovativas. Nota-se que, nesse modelo, não existe a capacidade de imitação de estratégias inovativas.

No modelo proposto neste artigo, o grau de "cegueira" das firmas em relação aos eventos futuros e aos que ocorrem no âmbito externo das mesmas é levado a um valor extremo, que vai além do que foi proposto por Silverberg e Verspagen (1994), pois, nesse modelo, as firmas têm informação a respeito da taxa de crescimento das empresas concorrentes. Aqui, a hipótese de cegueira foi introduzida para aumentar o grau de "ignorância" das firmas, o que torna o modelo mais condizente com a ideia de que a emergência de padróes de conduta no conjunto das empresas é uma propriedade inesperada do ponto de vista da conduta individual dessas firmas.

9 É a racionalidade típica dos modelos neoclássicos. Os agentes conhecem a distribuição de probabilidade dos eventos futuros. 
Em outros termos, adota-se o pressuposto de que as decisões estratégicas das firmas operam com racionalidade extremamente limitada, indicando que elas dispõem de informações concretas sobre número limitado de eventos. Nesse sentido, os parâmetros de aprendizagem no âmbito das decisões estratégicas giram em torno de eventos cujas informações são de pleno domínio das firmas, a exemplo do lucro e do market share das vendas dessas firmas.

As informações que cada empresa dispõe a respeito dos preços, dos custos, dos gastos inovativos e do market share das vendas de suas rivais não são suficientemente confiáveis para balizarem suas estratégias inovativas. Menos confiáveis ainda são as distribuições de probabilidade dos eventos futuros, sejam estes internos ou externos ao âmbito da firma, não importando o tempo de vida desta. A realização de uma inovação a partir dos investimentos em P\&D é um exemplo de incerteza que ocorre no âmbito interno da empresa; uma incerteza cujo grau independente do tempo de vida da firma.

Para fins do modelo aqui proposto, as únicas informaçōes em que as firmas confiam plenamente quando avaliam a necessidade de mudança em suas estratégias inovativas são o lucro e o market share das vendas delas próprias e que estão sendo observados. Com base nessas informações, as empresas tomam suas decisões no campo das estratégias inovativas. A título de simplificação do modelo, o mark up e o coeficiente de capital são tomados como parâmetros do modelo, não cabendo decisōes estratégicas para eles.

Neste modelo, por conta de hipóteses simplificadoras, a performance competitiva depende exclusivamente do nível de preços (essa simplificação aparece no modelo de Silverberg e Verspagen). Esse nível, por sua vez, depende fundamentalmente das inovações de processo, as quais estão probabilisticamente associadas aos gastos com $P \& D$. Por conseguinte, esses gastos ocupam posição-chave no processo de avaliação das estratégias competitivas das firmas, uma vez que eles constituem a única variável que as firmas podem controlar quando deparam com a necessidade de mudança em suas posições competitivas.

Nessa linha de raciocínio, as mudanças nas estratégias inovativas serão implementadas somente em caso de perda de market share das vendas ou de prejuízos. Se a firma perde market share, mas registra lucros positivos, ela interpreta esses resultados como sinal de que os níveis de investimento em $\mathrm{P} \& \mathrm{D}$ são inadequados para sustentar uma boa performance competitiva. A reação esperada é o aumento do percentual do valor das vendas alocado para os gastos com P\&D. Em caso de prejuízo, a necessidade de sobrevivência força a redução do percentual destinado a 
esses gastos. Numa situação em que há manutenção ou crescimento do market share das vendas, compartilhada com lucros positivos, as firmas são levadas à conclusão de que o percentual do faturamento destinado a P\&D é adequado para garantir boa posição competitiva.

Quanto ao processo de mudança tecnológica, são adotadas algumas simplificaçôes no modelo. As inovações são exclusivamente de processo, afetando somente a produtividade da mão de obra, o que reflete diretamente no custo médio de produção. Não existe o efeito de safra tecnológica (presente no modelo de Silverberg e Verspagen), indicando que o sucesso inovativo não se repete dentro do mesmo intervalo de tempo. O modelo opera, portanto, com distribuição de probabilidade do tipo binominal, sendo cada intervalo de tempo a base de realização do evento probabilístico, que se resume no sucesso ou fracasso da inovação. Essa probabilidade varia positivamente com o percentual de gastos com P\&D das firmas. Contudo, por hipótese, as empresas não têm conhecimento preciso da relação entre os gastos com P\&D e a probabilidade do sucesso inovativo.

De acordo com a hipótese de "cegueira" das firmas, formulada anteriormente, estas desconhecem os mecanismos de causalidade e as interatividades que regem a dinâmica da competição. Elas não têm ideia precisa de como operam esses mecanismos; não sabem exatamente quais as variáveis-chave dessa dinâmica e não possuem capacidade de formular um modelo explicativo plenamente confrável. Inúteis para elas são os conceitos de curva de demanda e de elasticidade-preço da demanda. Obviamente, o mecanismo de seleção existe e foi modelado de acordo com o princípio da seleção natural, conhecido como princípio de Fisher, matematicamente definido pela equação replicadora (SILVERBERG, 1988, 1997) e muito utilizado em modelos de economia evolucionária. O único campo em que as firmas são poupadas de eventos futuros incertos é o da aplicação da nova tecnologia. Sabem elas que a realização de um sucesso inovativo impacta diretamente a produtividade da mão de obra, reduzindo o custo médio e o preço final da produção.

Outra simplificação do modelo é a ausência de entrada ou saída de firmas no mercado. Não obstante, as empresas que não lograram êxito relativo nas suas atividades inovativas e que foram empurradas para um market share próximo de zero ficarão impedidas de realizarem gastos com $\mathrm{P} \& \mathrm{D}$ e condenadas à probabilidade zero de sucesso inovativo, ficando, em termos relativos, excluídas do mercado.

A ênfase na dimensão microeconômica é outro aspecto relevante do modelo. A noção de induistria é posta concomitantemente à noção de regime tecnológico. 
Então, deve-se reconhecer o fato de que parte significativa dos gastos que garantem a demanda da indústria em análise é exogenamente determinada (depende da renda gerada nas demais indústrias da economia). Cada indústria "abocanha" uma parte do gasto total da economia. O fluxo de inovação, em especial as inovações de produto, pode ser um dos determinantes da participação de cada setor nesse total de gastos. Para fins de simplificação do modelo, será adotada a hipótese de que essa participação é constante.

A seguir apresenta-se o conjunto de equaçóes do modelo, o qual define matematicamente as relações de causalidade mostradas no referencial teórico e nas linhas básicas do modelo.

\section{Equações do modelo}

O conjunto de equações do modelo está dividido em três blocos. O primeiro é composto de equações que captam as interaçôes de mercado das firmas, determinando o desempenho econômico (vendas e lucros) destas - nesse bloco é definido o mecanismo de seleção (dinâmica de mercado). No segundo bloco, que versa sobre a dinâmica tecnológica no âmbito da firma, são especificados a distribuição de probabilidade dos eventos inovativos e o processo de mudança tecnológica, sendo descritas as funções relativas às fontes geradoras e ao impacto dessa mudança em termos de inovações de processo (nesse modelo não ocorrem inovações de produto). No último bloco é especificada a dinâmica da aprendizagem, sendo ele composto por um número reduzido de equaçôes, refletindo as restritas possibilidades de aprendizagem no campo das decisões estratégicas.

\subsection{Bloco da dinâmica seletiva}

De acordo com as linhas básicas do modelo, a demanda da induistria ${ }^{10}$ é representada pela parcela da renda nacional que é gasta com os produtos dessa indústria. $\mathrm{O}$ valor total das vendas para o conjunto das firmas do modelo é dado pelas seguintes equaçōes:

10 Para os propósitos deste artigo, é suficiente o uso da noção de indústria típica dos manuais de microeconomia: conjunto de firmas que atuam em um mesmo mercado. Entretanto, o modelo permite uma definição de cunho evolucionário: o conjunto de firmas que simultaneamente exploram as oportunidades tecnológicas criadas a partir do artefato (DOSI, 1988) que inaugura um novo paradigma tecnológico. 
$Q_{t}=\left(Y_{t}+L_{t} w\right) \psi$

$Y_{\mathrm{t}}=Y_{0} e^{r t}$

$L_{\mathrm{t}}=\sum_{i=1}^{n} L_{i, t}$

sendo $Q=$ valor total das vendas (subscrito $t$ indica tempo) do conjunto das $n$ firmas que formam a indústria simulada; $Y=$ renda nacional; $r=$ taxa de crescimento da renda nacional; ${ }^{11} L_{t}=$ total de trabalhadores empregados na indústria simulada; $L_{i, t}=$ nível de emprego gerado pela firma $i ; \psi=$ parcela da renda nacional gasta na compra de produtos da indústria simulada; $w=$ taxa de salário. ${ }^{12}$

De acordo com a equação (3), a demanda da indústria simulada é composta de uma variável exógena $(Y)$ e uma variável endógena $(L w)$. O parâmetro $\psi$ é constante, indicando que a atividade inovativa não impacta a parcela da renda nacional gasta com produtos da indústria simulada.

O nível de emprego gerado em cada firma é dado pela seguinte equação:

$L_{i, t+1}=Q i, t / a i, t$

em que $L_{i}=$ nível de emprego da firma $i ; Q_{i, t}=$ valor das vendas da firma $i ; a_{i, t}=$ produtividade da mão de obra da firma $i$.

A dinâmica seletiva é regida pelo seguinte conjunto de equações:

$Q_{i, \mathrm{t}}=s_{i, \mathrm{t}} Q_{\mathrm{t}}$

$\Delta s_{i, \mathrm{t}+1}=\phi\left(1-P_{i, / p}\right) s_{i, \mathrm{t}}$

$P_{\mathrm{t}}=\sum_{i=1}^{n} s_{i, \mathrm{t}} P_{\mathrm{i}, \mathrm{t}}$

$P_{\mathrm{i}, \mathrm{t}}=(1+\tau) \mathrm{w} / a_{i, \mathrm{t}}$

11 As mudanças de valores das variáveis do modelo carregam uma noção de tempo real equivalente ao período de um ano. Assim, o valor de $r$ foi igualado a 0,04, que é uma taxa de crescimento anual de longo prazo aproximadamente igual às médias nacional e mundial nas últimas décadas.

12 No modelo não existe dinâmica para o índice geral de preços. A taxa de salário real é constante. 
sendo: $s_{i, t}=$ market share das vendas da firma $i ; P_{i}=$ nível de preço da firma $i ; P$ $=$ média dos níveis de preço do conjunto de $n$ firmas; $\tau$ = mark up (por hipótese simplificadora, todas as firmas praticam o mesmo mark up).

A equação (8) é uma peça central da dinâmica competitiva. Nos termos dessa equação, as firmas em desvantagem competitiva $\left(P_{i, t}>P_{t}\right)$ perdem market share das vendas. No entanto, a despeito dessa perda, essas firmas podem sobreviver por período de tempo relativamente longo, dependendo do valor do parâmetro $\phi$. Inclusive, haverá tempo suficiente para a firma reverter essa desvantagem, dependendo da evolução da sua atividade tecnológica e do seu sucesso inovativo. Nessa dinâmica, vai sendo preservada a heterogeneidade (de estratégia, de tamanho, de produtividade, etc.) da indústria.

\subsection{Bloco da dinâmica tecnológica}

As equaçôes deste bloco foram elaboradas sob a égide teórica das contribuições de Cohen e Levinthal (1989) e Silverberg e Versbagen (1994). Conforme indicado nos termos das equações (1) e (2), a dinâmica tecnológica do modelo é fruto de uma síntese entre essas duas contribuições. Essa tentativa deu origem ao seguinte conjunto de equações:

$$
\begin{aligned}
& a_{i t}^{*}=\left[(1+\lambda) a_{i, t}\right] P r_{i, t} \\
& P r_{i, t}=P(X=1)=1-e^{-a^{T T} T_{i, t}} \\
& a_{i, t+1}=\max \left(a_{i, t}, a_{i, \mathrm{t}}^{*}\right) \\
& T_{i, \mathrm{t}}=R D_{i, t}+\gamma_{i, t}\left(\theta \sum_{i=1}^{n} R D_{i, t}+\mathrm{J}\right) \\
& \gamma_{i, t}=1-e^{-\beta b_{i, t}} \\
& T T_{i, t}=T_{i, t}\left(1+\operatorname{Klog}\left({ }^{\max , t} / a_{i, t}\right)\right. \\
& a_{\text {max }, t}=\max \left(a_{1, t,} a_{2, t} \ldots a_{n, t}\right)
\end{aligned}
$$


$R D_{i, t}=b_{i, t} P_{i, t} Q_{i, t}$

em que: $a_{l}^{*}=$ produtividade da mão de obra (o subscrito $i$ é o identificador da firma), resultante da mudança tecnológica; $a_{i}=$ produtividade da mão de obra efetivamente operada pela firma $i ; \lambda=$ índice de avanço tecnológico (por hipótese simplificadora, é igual para todas as firmas); $P r_{i}=$ probabilidade de sucesso inovativo (distribuição binominal); $T_{i}=$ fator que define a probabilidade de sucesso inovativo; $R D_{i}=$ total de gastos com P\&D; $\gamma_{i}=$ índice de capacidade absortiva; $\theta=$ grau de spillover $; \mathrm{J}=$ grau de oportunidade tecnológica; $b_{i}=$ relação $\mathrm{P} \& \mathrm{D} /$ vendas da firma $i ; \beta=$ grau de complexidade da base de conhecimento; $T T_{i}=$ parâmetro da função de distribuição de probabilidade do evento inovativo; $\alpha$ e $\kappa=$ parâmetros do modelo.

As equações (11) e (16) foram extraídas do modelo de Silverberg e Verspagen (1994). A equação (14), por sua vez, foi formulada de acordo com os argumentos teóricos de Cohen e Levinthal (1989), mas devidamente adaptada para incorporar os elementos de incerteza-probabilísticos típicos da atividade inovativa. Assim, esse conjunto de equações é a concretização do projeto de modelagem desenhado no referencial teórico.

A equação (15) carrega o elemento-chave da definição dos cenários. O parâmetro $\beta$ capta o grau de complexidade da base de conhecimento, cujos efeitos sobre a capacidade absortiva das firmas foram analisados no referencial teórico (Gráfico 1). Quanto menor o valor de $\beta$, maior o grau de complexidade e, portanto, menor a capacidade de absorção de conhecimentos externos da empresa para um dado montante de P\&D; quanto menor essa capacidade, menor a probabilidade de sucesso inovativo. Um regime tecnológico com alto grau de complexidade da base de conhecimento implica a necessidade de uma relação $\mathrm{P} \& \mathrm{D} /$ vendas de alto valor para a firma usufruir dos conhecimentos externos e do efeito catching up. Contudo, esse esforço pode comprometer os resultados financeiros da empresa, pois o gasto com P\&D é contabilizado no modelo como custo indireto da produção (equação 19). Opostamente, um regime com baixo grau de complexidade da base de conhecimento implica alta capacidade de absorção do conhecimento externo para esforços inovativos relativamente baixos. Nesse tipo de regime é esperada uma situação de desvantagem para as firmas que adotam estratégias agressivas de P\&D. O sucesso inovativo dessas firmas "vaza" para as rivais com estratégias menos agressivas, as quais concomitantemente são poupadas do sacrifício financeiro decorrente da adoção de estratégias inovativas agressivas. 


\subsection{Bloco da dinâmica de aprendizagem}

Segundo as linhas básicas do modelo, as firmas adquirem experiência a respeito da melhor estratégia por meio de um longo processo de tentativa e erro. Elas não têm capacidade de conhecer e muito menos prever as estratégias adotadas pelas rivais. Muito menos ainda, podem elas prever os resultados futuros de cada estratégia adotada. Resta então às firmas avaliar os resultados concretos que elas definitivamente conhecem, isto é, os resultados que são exclusivos do âmbito interno da firma, tais como o lucro e o market share observados - considerados importantes indicadores de avaliação do desempenho competitivo.

As regras de aprendizagem e seleção das estratégias inovativas são definidas de acordo com o seguinte esquema:

$\Pi_{\mathrm{i}, \mathrm{t}}=P_{\mathrm{i}, \mathrm{t}} Q_{\mathrm{i}, \mathrm{t}}-\mathrm{L}_{\mathrm{i}, \mathrm{t}} \mathrm{w}-\mathrm{RD}_{\mathrm{i}, \mathrm{t}}$

$\operatorname{Se}\left\{\begin{array}{l}\Pi_{\mathrm{t}}>0 \\ \mathrm{e} \\ \Delta s_{i, \mathrm{t}}>0, \text { então } b_{i, t+1}=b_{i, t}\end{array}\right.$

$\operatorname{Se}\left\{\begin{array}{l}\Pi_{\mathrm{t}}>0 \\ \mathrm{e} \\ \Delta s_{i, \mathrm{t}}<0, \text { então } b_{i, t+1}=(1+v) b_{i, t}\end{array}\right.$

Se $\Pi_{\mathrm{t}} \geq 0$; então $b_{i, t+1}=(1-\eta) b_{i, t}$

em que: $\Pi$ = lucro da firma $i$ (por simplificação, foi adotada a hipótese de que não existem gastos com matéria-prima nem depreciação). 
Nesse conjunto de regras, o primeiro destaque é a observação de que as firmas avaliam o resultado de suas estratégias uma vez a cada período. A escala temporal pensada neste modelo é equivalente a uma série com períodos anuais. Isso significa que as empresas demandam um período equivalente a um ano para concluir o processo de avaliação de suas estratégias inovativas. Os parâmetros $v$ e $\eta$ são positivos e menores que um. Então, ocorrem três situações distintas. A primeira corresponde àquela em que a firma registra lucro positivo e aumento ou manutenção do market share das vendas. Nesse caso, existe no âmbito da firma a convicção de que a estratégia adotada é uma boa escolha, não havendo necessidade de mudá-la. Na segunda situação, é registrado lucro positivo, porém houve perda de market share, criando dentro da firma pressōes para mudar a estratégia inovativa, devido à ameaça de perda de mercado. Visto que a empresa ainda dispõe de margem positiva de lucro, é natural imaginar a ocorrência de pressōes internas para o aumento dos recursos destinados aos investimentos em P\&D. No caso específico deste modelo, a estratégia inovativa é a única maneira de se buscar uma melhoria do desempenho competitivo via redução dos custos e dos preços. No entanto, vale lembrar que as firmas não dispõem de um modelo de competição em que elas podem depositar absoluta confiança. Elas não têm certeza a respeito das variáveis-chave da competição e muito menos sobre as relações de causalidade envoltas na dinâmica de seleção do mercado. O aumento dos gastos com P\&D foi modelado como sendo única via ao alcance das firmas para tentar melhorar o desempenho de mercado.

A última situação comporta uma reação típica de sobrevivência. Ao contabilizarem prejuízo ou lucro zero, as firmas tomam medidas para minimizar as perdas, o que implica obviamente o corte de gastos - em especial dos gastos que não comprometem suas atividades operacionais.

\section{Resultados da simulação}

A parte central do modelo é composta por dez subgrupos de equações, cada um representando uma firma. O bloco de dinâmica seletiva (equaçōes 7 a 10) e a equação de catching up (equação 16) formam os canais de interação entre esses subgrupos. De acordo com as linhas básicas do modelo, o número de firmas não se altera ao longo da simulação, característica essa presente nos modelos de Cohen e Levinthal (1989) e de Silverberg e Verspagen (1994). Contudo, algumas empresas poderão 
sofrer perda significativa do market share a ponto de se tornarem irrelevantes em termos dos resultados finais da simulação.

Apenas dois cenários foram realizados. O primeiro representa o contexto de um regime tecnológico com alto grau de complexidade da base de conhecimento (parâmetro $\beta$ da equação 15 igual à unidade) e alto grau de oportunidade tecnológica (parâmetro $J$ da equação 14 designado com um valor considerado elevado, sendo igualado a 10). O outro cenário corresponde a um regime tecnológico com baixo grau de complexidade da base de conhecimento (parâmetro $\beta$ igual a 10) e alto grau de oportunidade tecnológico (parâmetro $J$ igual a 10). As trajetórias produzidas nesses dois cenários fornecerão os dados para a análise da importância do regime tecnológico como fator determinante da emergência dos padrôes de mudança tecnológica da indústria simulada.

Os valores iniciais do parâmetro $b_{i}$ (equação 14 ) foram arbitrariamente designados com enorme discrepância entre as dez firmas, sendo estipulados dentro do intervalo de 0,01 até 0,5. Essa escolha arbitrária é uma forma estilizada de captar um fenômeno típico da emergência de um novo paradigma tecnológico: a ausência de um padrão de estratégia inovativa. ${ }^{13}$ Por outro lado, o market share inicial de cada firma é igual a 10\%, sendo iguais também os valores iniciais da produção, da produtividade, do custo médio e dos preços, indicando que, na fase de emergência do novo paradigma, o poder competitivo das firmas está nivelado, a despeito das diferenças em termos de estratégias inovativas. Somente no longo prazo essas diferenças vão se refletir no poder competitivo de cada firma e desembocar na convergência dessas estratégias.

Conforme mostrado no Gráfico 2 , a média de $b_{i}$ diminui de forma significativa até o trigésimo período em ambos os cenários. Essa queda indica que as firmas que optaram inicialmente por uma alta taxa de investimento em P\&D foram as que apresentaram os piores resultados em termos de desempenho econômico.

13 A heterogeneidade das estratégias inovativas visando explorar as oportunidades tecnológicas geradas pelo novo paradigma é um fato estilizado da microeconomia evolucionária (DOSI et al., 1990; BELL; PAVITT, 1993). Um dos grandes desafios da economia evolucionária é a modelagem da formação de padrões de estratégia inovativa sem abordar o princípio da heterogeneidade. A noção de "atrator" explorada brilhantemente no artigo de Silverberg e Verspagen (1994) foi a solução encontrada por esses autores para conciliar os princípios da heterogeneidade e da convergência. 
GRÁFICO 2

Série temporal do valor médio de $b_{i}$ (P\&D/vendas) de cada cenário, calculado para as dez firmas nas dez rodadas de simulação

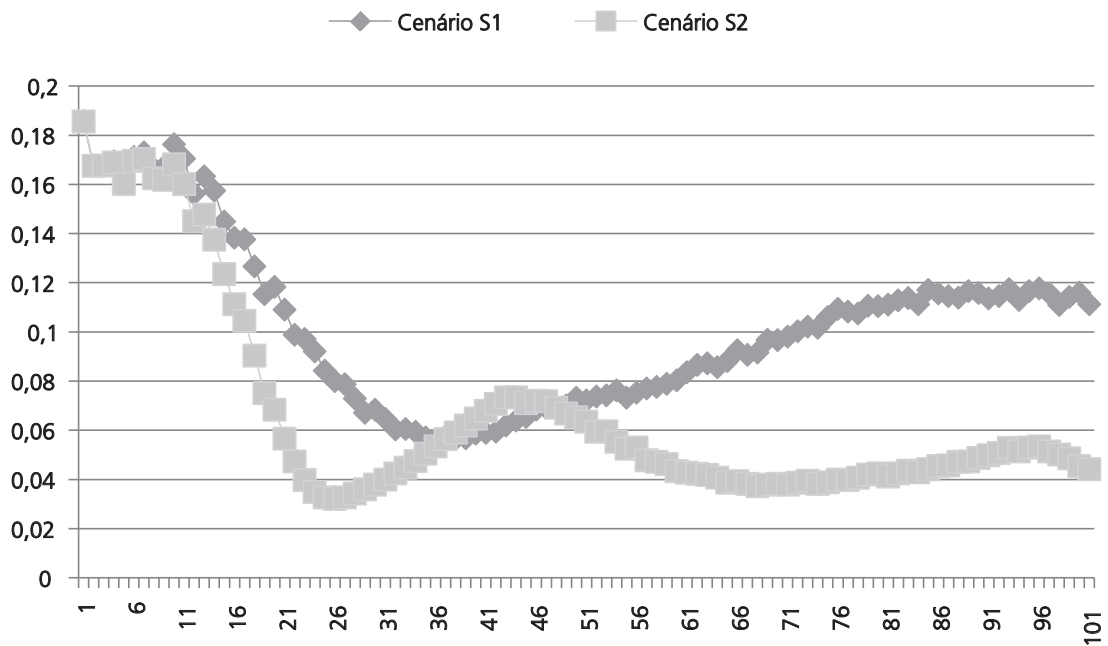

Fonte: Elaboração dos autores, com base nas simulaçôes.

Somente a partir do quinquagésimo período ficam nítidas as tendências de cada uma das trajetórias. Em alguns momentos, os valores da série temporal gerada no cenário S2 ultrapassam aqueles produzidos no cenário S1. Esses "retardo" e "balanço" antes da consolidação das tendências de cada uma dessas séries são reflexo da dinâmica competitiva produzida pela equação replicadora (equação 8 , cujo parâmetro $\phi$ foi designado com um valor relativamente baixo, sendo igualado a 0,1 ). Por conta desse parâmetro, os diferenciais do poder competitivo de cada firma só se manifestam no longo prazo e por meio de efeitos defasados.

Os resultados mostrados no Gráfico 2 são condizentes com a hipótese de que o alto grau de complexidade da base de conhecimento é um fator que eleva a taxa de investimento em P\&D (parâmetro $b_{i}$ ). Entretanto, ao contrário do que sugerem Cohen e Levinthal (1989), esse ajuste não é automático, podendo levar um longo período de tempo - na simulação, levou aproximadamente 50 anos, valendo a hipótese de que as firmas ajustam suas estratégias uma vez a cada ano.

Cada rodada de simulação se traduz em um experimento estatístico. Desse modo, podem ser produzidas distintas trajetórias dentro do mesmo cenário. Nos Gráficos 3 e 4 estão registradas as trajetórias das médias de $b_{i}$ (média ponderada entre as dez firmas) nas dez rodadas de simulação de cada cenário. No cenário $\mathrm{S} 1$, a maior parte dos valores ficou acima de 0,08 a partir do quinquagésimo período. 
Já no cenário S2, a maior parte ficou abaixo de 0,08 a partir desse mesmo período. Algumas séries, no entanto, quebram essa regra, fazendo com que os valores do cenário S2 suplantem os produzidos no $S 1$.

\section{GRÁFICO 3}

Série temporal do valor médio de $b_{i}$ (P\&D/vendas) das dez firmas em cada rodada de simulação, para o cenário S1

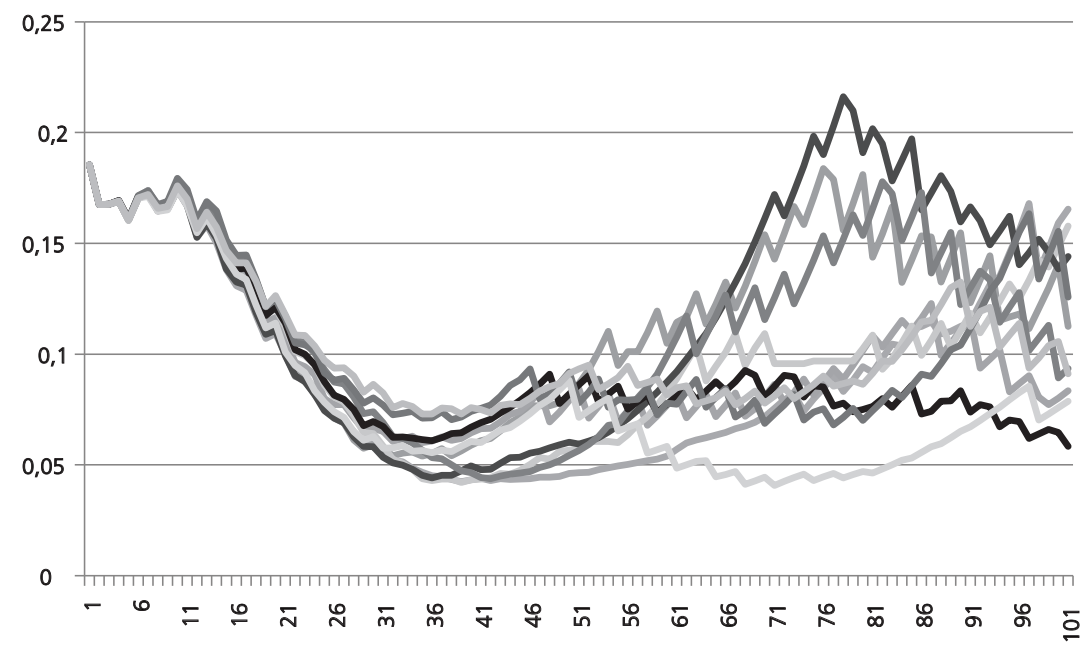

Fonte: Elaboração dos autores, com base nas simulações.

\section{GRÁFICO 4}

Série temporal do valor médio de $b_{i}$ (P\&D/vendas) das dez firmas em cada rodada de simulação, para o cenário S2

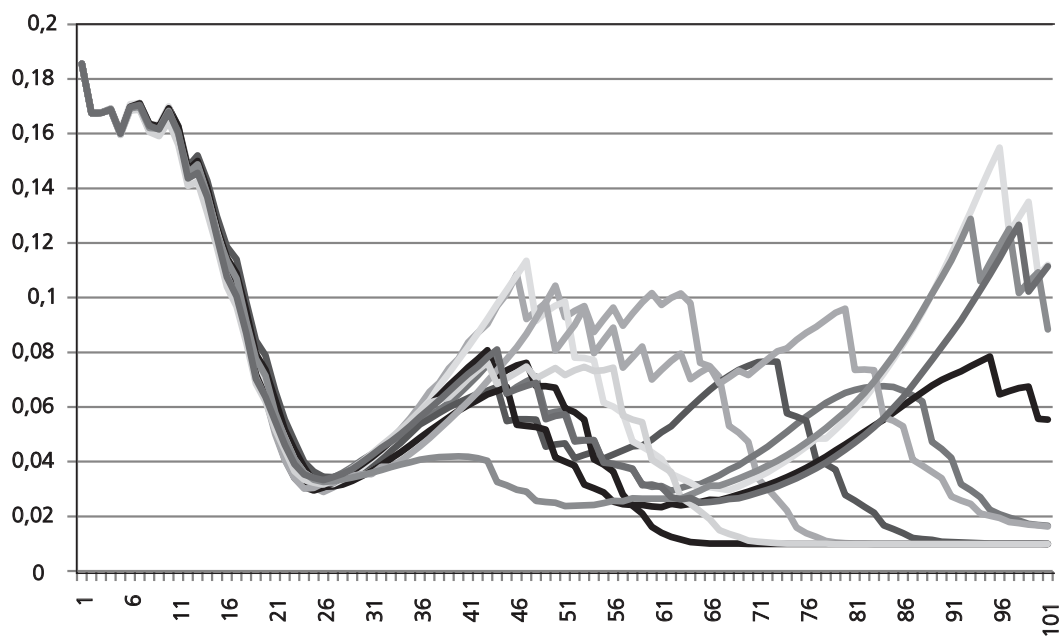

Fonte: Elaboração dos autores, com base nas simulações. 
Esses dados mostram a possibilidade de um regime tecnológico com alto grau de complexidade evoluir para uma intensidade relativamente baixa em termos de investimento em P\&D ou vice-versa. No âmbito da simulação, esse é um fenômeno relativamente raro, mas serve para demonstrar a possibilidade da ocorrência de padrões distintos em termos de estratégia inovativa dentro de uma mesma indústria, dependendo do contexto. No caso específico da simulação, esse contexto é caracterizado exclusivamente pelos valores de $b_{i}$ e pelas realizaçōes probabilísticas do início da simulação.

Vale notar que essa diversidade de trajetórias dentro do mesmo regime não se altera em função do efeito catching up (equação 16). Resultados praticamente idênticos foram obtidos nas rodadas de simulação com os valores de 0,1 e 1 designados ao parâmetro $\kappa$, o que indica a irrelevância desse efeito. Na verdade, o catching up está incluso no conceito de capacidade absortiva (parâmetro $\gamma$, equação 14) formulado por Cohen e Levinthal (1989). Nessa formulação, o conceito de catching up carrega a concepção de spillover e de oportunidade tecnológica, pondo em evidência a complexidade do fenômeno do catching up. Outro cenário não contemplado, mas que poderia produzir os mesmos resultados quanto ao papel do catching up, é relativo ao regime tecnológico com baixo grau de spillover e de oportunidade tecnológica. Nesse caso, sequer existem as condiçōes de ocorrência do catching up, pois todo esforço de $\mathrm{P} \& \mathrm{D}$ para aumentar a capacidade absortiva não lograria êxito, visto não haver conhecimentos aptos a serem absorvidos.

A tendência de aumento ou de queda do valor médio da intensidade de P\&D das firmas (parâmetro $b_{i}$ ) - dependendo do regime tecnológico - e a convergência das estratégias inovativas são os fatos estilizados que caracterizam a emergência dos padrōes de mudança tecnológica. Com relação ao fenômeno da convergência, foi analisada a série temporal da média da variância de $b_{i}$, calculada em cada um dos cenários, cujos valores estão plotados no Gráfico 4.

Em ambas as séries, a tendência nítida de queda só vai emergir a partir do trigésimo período. Salvo a queda abrupta no primeiro período, as disparidades das estratégias inovativas persistem durante um intervalo de tempo relativamente longo, indicando que a aprendizagem no campo das decisões estratégias é um processo lento e oneroso (perda de market share), para algumas firmas. As empresas mudam inúmeras vezes suas estratégias em meio ao processo de tentativas e erros, selecionando lentamente as estratégias mais promissoras em termos de desempenho competitivo e econômico.

No transcorrer desse processo de aprendizagem, algumas firmas sucumbem antes de conhecerem a estratégia condutora do sucesso inovativo e competitivo. Essas empresas são malsucedidas em termos da escolha das estratégias inovativas e/ou do 
evento inovativo (realização do sucesso inovativo em cada período da simulação) nos primeiros períodos da simulação. As firmas que acumulam sucessos inovativos, combinados com decisões estratégicas que não geram prejuízo, tendem a crescer em ritmo mais acelerado perante suas rivais malsucedidas, dispondo assim de um volume de recursos para inovação relativamente maior, o que aumenta a probabilidade de sucesso dessa atividade em relação às firmas que ficaram com porte menor.

\section{GRÁFICO 5}

Valor médio da variância de $b_{i}$ (P\&D/vendas) nas dez rodadas de simulação de cada cenário

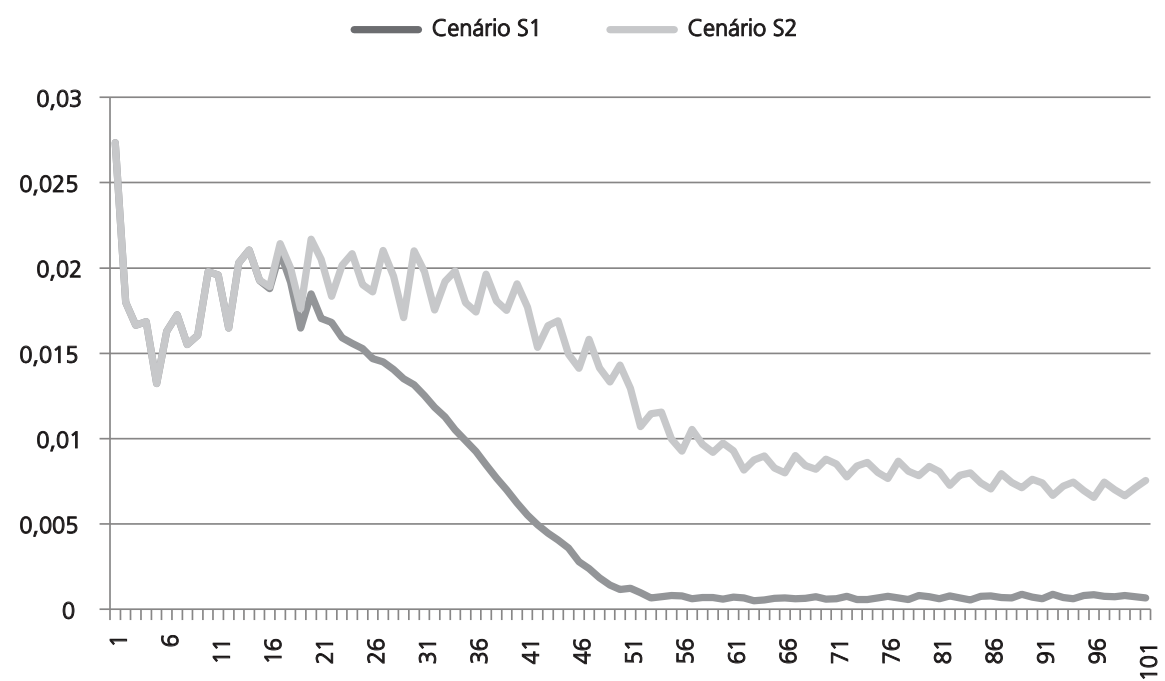

Fonte: Elaboração dos autores, com base nas simulações.

Essa sobreposição dos efeitos randômico e cumulativo no processo inovativo desemboca numa tendência de concentração de mercado, registrada nos Gráficos 5 e 6, a qual é sensível aos eventos ocorridos nos primeiros períodos da simulação. São esses eventos que provocam uma disparidade significativa no valor final do índice de concentração da produção (índice Herfindahl-Hirschman), constatada nos cenários S1 e S2. No cenário S1, uma das trajetórias termina com o índice pouco acima de 4.000 , enquanto outra termina próximo de 8.000 , ou seja, praticamente o dobro da concentração. Algo semelhante acontece no cenário S2. Ao final do centésimo período, uma das trajetórias foi finalizada com um valor pouco abaixo de 6.000. Em compensação, outra trajetória atingiu grau máximo de concentração antes do término do sexagésimo período. 
Resultado muito importante é a constatação de que a tendência de concentração é mais forte no cenário $\$ 2$, cujo regime tecnológico é caracterizado pelo baixo grau de complexidade da base de conhecimento, tendo um padrão de mudança tecnológico marcado pela baixa intensidade de P\&D. Quer dizer, o setor menos intensivo em P\&D apresenta forte tendência à concentração da produção, se comparado ao setor mais intensivo em P\&D. Lembrando que o modelo não incorpora economias de escala, então é o próprio processo de mudança tecnológica o causador dessa concentração.

A explicação desse fenômeno reside no mecanismo de absorção do conhecimento externo, o qual é mais poderoso no cenário S2. As firmas que optaram pelas estratégias de alta intensidade de $\mathrm{P} \& \mathrm{D}$, no início da simulação, vão alimentar o sucesso inovativo das firmas com baixa intensidade de $\mathrm{P} \& D$. Estas, por sua vez, vão obter lucros mais elevados no início da simulação, não somente porque investiram menos em P\&D, mas também porque se beneficiaram dos conhecimentos gerados por suas rivais que adotaram estratégias inovativas mais agressivas. Esse duplo efeito acelera o crescimento do market share das firmas que foram bem sucedidas no início da simulação. No cenário S1 a situação é um pouco diferente. Apesar do processo cumulativo, a absorção do conhecimento é mais limitada, pois o regime tecnológico é caracterizado pelo alto grau de complexidade da base de conhecimento. Somente as firmas com estratégias mais agressivas de $\mathrm{P} \& \mathrm{D}$ podem usufruir dos conhecimentos gerados externamente. No entanto, essas firmas esbarram na debilidade financeira, produzida justamente pelos gastos elevados em P\&D. O recuo em sua agressividade, combinado com a baixa capacidade de absorção das demais empresas, reduz a probabilidade de sucesso inovativo da maioria das firmas, o que impede a formação de um fosso profundo entre as firmas bem e mal sucedidas.

Com esses resultados, ficam delineados dois quadros de mudança tecnológica e de estrutura de mercado, resultantes dos imperativos estabelecidos pelo regime tecnológico. No regime com alto grau de complexidade da base de conhecimento, combinado com alto grau de spillover e de oportunidade tecnológica, emerge um padrão tecnológico caracterizado por intensidade de $\mathrm{P} \& \mathrm{D}$ (variável $b_{i}$ ) relativamente alta (valor médio próximo de 0,12 no final da simulação) e com grau de concentração da produção relativamente baixo (índice de Herfindahl-Hirschman que raramente ultrapassa 6.000 no final do centésimo período). Com um grau de complexidade baixo, as tendências se invertem, baixando a intensidade de P\&D e elevando o grau de concentração da produção (com a maioria atingindo índice de Herfindahl-Hirschman igual a 10.000 entre o sexagésimo e o centésimo período). 


\section{GRÁFICO 6}

Série temporal do índice de Herfindahl-Hirschman de cada rodada de simulação, no cenário S1

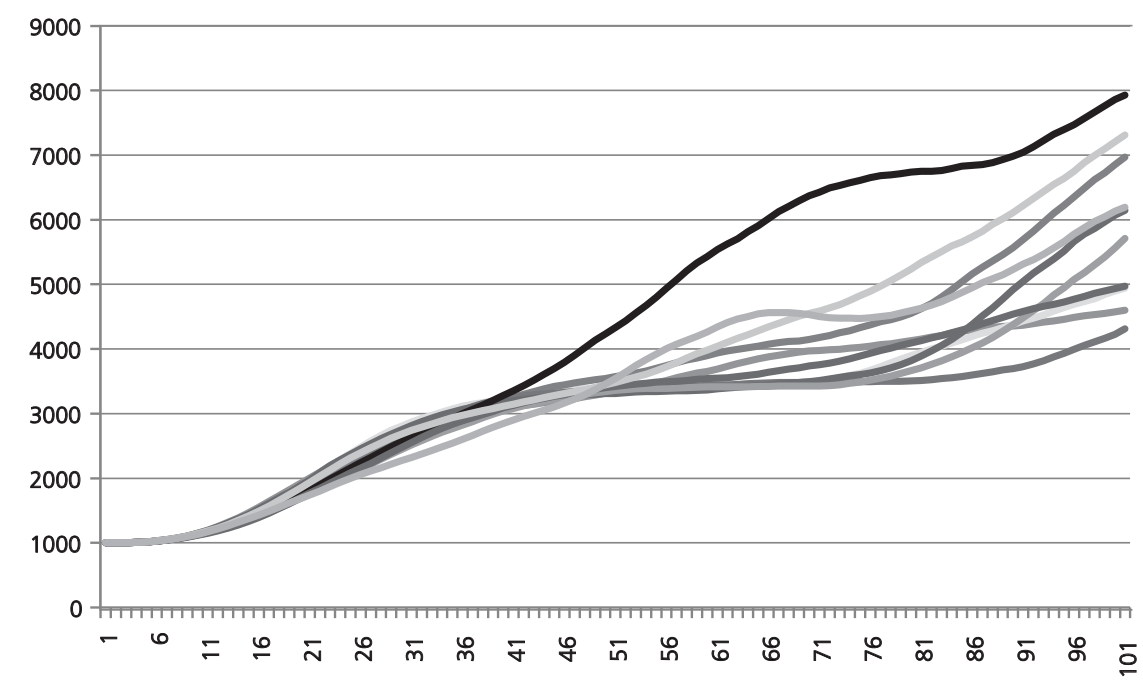

Fonte: Elaboração dos autores, com base nas simulaçōes.

\section{GRÁFICO 7}

Série temporal do índice de Herfindahl-Hirschman de cada rodada de simulação, no cenário S2

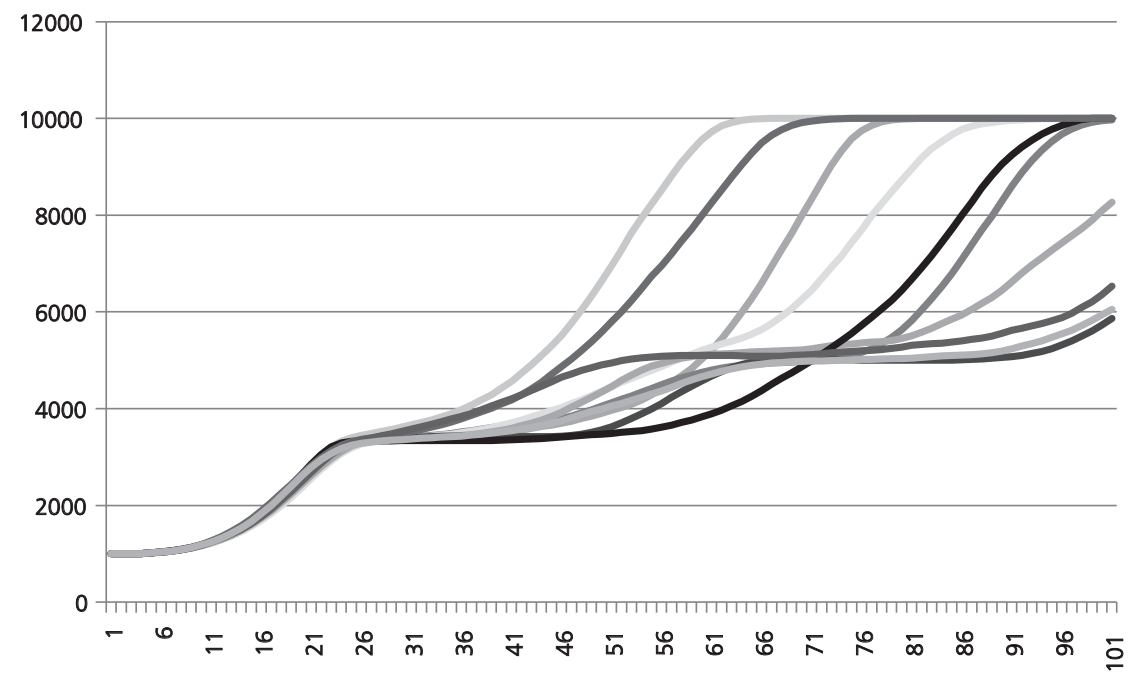

Fonte: Elaboração dos autores, com base nas simulações. 


\section{Conclusões}

Os imperativos econômicos (economias de escala, rendimentos decrescentes, barreiras à entrada, etc.) são pilares fundamentais da modelagem econômica, pois teoricamente cumprem o papel de condicionante das condutas que prevalecem dentro das firmas. $\mathrm{Na}$ economia evolucionária, são fundamentais as noções de paradigma tecnológico, trajetória tecnológica e regime tecnológico, que fornecem a pista para o entendimento das forças condicionantes das decisões tecnológicas dentro das empresas.

A decifração dos nexos de causalidades entre os imperativos tecnológicos e as condutas reinantes dentro das firmas é a questão motivadora desta pesquisa. Essa investigação foi realizada com base em um modelo de simulação, o qual é formado por um conjunto de equações, cujos termos representam a tradução quantitativa dos conceitos de regime tecnológico, capacidade absortiva e equação replicadora. As relações de causalidade expressas nessas equações advêm das noções evolucionárias de firma, indústria e mercado. As firmas são o lócus da aprendizagem e dos avanços tecnológicos. A indústria, por sua vez, representa o conjunto de firmas rivais, isto é, o conjunto de empresas que competem entre si no desenvolvimento e aperfeiçoamento de um artefato tecnológico. Esse artefato, bem como toda a heurística envolvida em seu desenvolvimento e aperfeiçoamento, concretiza um novo paradigma tecnológico.

O regime tecnológico foi definido como os parâmetros-chave que condicionam o processo de aprendizagem tecnológica de onde provêm as soluções tecnológicas para esse artefato.

Em regimes tecnológicos cujos parâmetros facilitam (dificultam) a imitação e a transferência de tecnologia, isto é, regimes em que as firmas possuem alto (baixo) grau de capacidade absortiva com pouco (alto) esforço de aprendizagem tecnológica, é intuitivo imaginar que as indústrias irão evoluir para um padrão de estratégia inovativa com baixa (alta) intensidade de P\&D. De fato, essa foi a conclusão de alguns estudos evolucionários importantes. O objetivo deste artigo foi analisar teoricamente de que modo o regime tecnológico condiciona o surgimento desses padrôes em um contexto de incertezas tecnológicas e econômicas.

Os resultados das rodadas de simulação geraram conclusões condizentes com as de outros estudos que investigam o papel do regime tecnológico na determinação da conduta das firmas. Contudo, em função de algumas particularidades do modelo aqui apresentado, a exemplo da racionalidade extremamente limitada e da determinação cumulativa-estocástica entre capacidade absortiva e sucesso inovativo 
das firmas, essas conclusões trazem à tona novas reflexões para o estudo da dinâmica tecnológica e industrial. A primeira delas é que a emergência dos padrões industriais de estratégia tecnológica das firmas é condicionada não somente pelas características do regime tecnológico, mas também pelas condições iniciais da simulação, indicando que o contexto histórico é também de crucial importância para a determinação desses padrôes. Nessa perspectiva, é possível que a mesma indústria, em economias diferentes, possa apresentar padrões de estratégia inovativa também diferentes. Outra conclusão importante diz respeito ao tempo necessário para a emergência desse padrão, que pode ser relativamente longo, dependendo das características da dinâmica seletiva e do tempo necessário para as firmas reavaliarem suas estratégias inovativas. Notou-se também que os regimes tecnológicos pouco intensivos em $\mathrm{P} \& \mathrm{D}$ possuem maior propensão à concentração da produção, mesmo na ausência da hipótese de economias de escala. Nesse caso, as economias de escala e a concentração de mercado emergem como subprodutos da dinâmica tecnológica.

\section{Referências bibliográficas}

AZARIADIS, C. Intertemporal macroeconomics. Oxford: Blackwell Publishers, 1998.

BELL, M.; PAVITT, K. Technological accumulation and industrial growth: contrasts between development and developing countries. Industrial and Corporate Change, n. 2, v. 2, p. 157-210, 1993.

BENHABIB, J. Cycle and chaos in economic equilibrium. New Jersey: Princeton University Press, 1992.

BROCK, W. A.; MALLIARIS, A. G. Differential equations, stability and chaos in dynamic economics. Amsterdam: North-Holland, 1989.

CHIAROMONTE, F.; DOSI, G. The micro foundations of competitiveness and their macroeconomic implications. In: FORAY, D.; FREEMAN, C. Technology on the wealth of nations. The dynamics of constructed advantage. London: Pinter Publishers, 1993, p. 107-134.

COHEN, W.; LEVINTHAL, D. Innovation and learning: two faces of R\&D. The Economic Journal, v. 99, p. 569-596, 1989.

CROCCO, M. A. Uncertainty, techinical change and effective demand. Thesis (Doctorate). London: University London, 1999.

DOSI, G. Technological paradigms and technological trajectories: a suggested interpretation of the determinants and directions of technical change. Research Polity, n. 11, p. 147-162, 1982. 
. Sources, procedures and microeconomic effects of innovation. Journal of Economic Literature, v. 26, n. 3, p. 1120-1171, September 1988.

DOSI, G.; EGIDI, M. Substantive and procedural uyncertainty: an exploration of economic behaviours in changing environments. Journal of Evolutionary Economics, v. 1, n. 2, p. 145-68, 1991.

DOSI, G.; PAVITT, K.; SOETE, L. The economics of technical change and international trade: Brighton: Wheatsheaf, 1990.

KLEVORICK, A. K.; LEVIN, R. C.; NELSON, R.; WINTER, S. On the sources and significance of interindustry differences in technological opportunities. Research Policy, p. 185-205, 1995.

KUPFER, D.; ROCHA, F. Determinantes setoriais do desempenho das empresas industriais brasileiras. In DE NEGRI, J. A.; SALERNO, M. S. Inovaçôes, padrōes tecnológicos e desempenho das firmas industriais brasileiras. Rio de Janeiro: Ipea, 2005.

LAZONICK, W. Learning and the dynamics of international and competitive advantage. In: THOMSON, R. Learning and technological change. New York: St. Martins Press, 1993, p. $172-197$.

MALERBA, F.; ORSENIGO, L. Technological regimes and firms behaviour. Industrial and Coporate Change, n. 1, v. 2, p. 45-71, 1993.

. Technological regimes and sectoral patterns of innovative activities. Industrial e Corporate Change, n. 6, v. 1, p. 83-117, 1997.

MARSILI, O.; VERSPAGEN, B. Technological regimes and innovation: looking for regularities in dutch manufacturing. Eindhoven: University of Technology, 2001 (Working paper, ECIS). MARCILI, O.; ORSENIGO, L.; SALVATORE, R. Learning, market selection and the evolution of industrial structures. Small Business Economics, v. 7, n. 6, December 1995.

NELSON, R.; WINTER, S. G. An evolutionary theory of economic change. Cambridge, Massachusetts: Harvard University, 1982.

PAVITT, K. Sectoral patterns of technical change: towards a taxonomy and theory. Research Policy, n. 13, p. 343-373, 1984.

SILVERBERG, G. Modeling economic dynamics and technical change: mathematical approaches to self-organization and evolution. In: DOSI, G.; FREEMAN, C.; R. NELSON, R; SILVERBERG, G.; SOETE, L. (Eds.). Technical change and economic theory. London: Pinter, 1988, p. 531-559. 
SILVERBERG, G. Evolutionary modeling in economics: recent history and immediate prospects. Research memoranda 008. Maastricht Economic Research Institute on Innovation and Technology - MERIT, 1997. Disponível em: <http://ideas.repec.org/p/dgr/ umamer/1997008.html>.

SILVERBERG, G.; DOSI, G.; ORSENIGO, L. Innovation, diversity and diffusion: a self-organization model. Economic Journal, v. 98, n. 393, p. 1032-1054, December 1988.

SILVERBERG, G.; VERSPAGEN, B. Learning, innovation and economic growth: a long-run model of industrial dynamics. Industrial and Corporate Change, v. 3, n. 1, p. 199-223, 1994.

SHONE, R. Economic dynamics: phase diagrams and their economic application. New York: Cambridge University Press, 2002.

SIMON, H. From substantive to procedural rationally. In HAHN, F.; HOLLIS, M. Philosophy and economic theory. Oxford Readings in Philosophy. Oxford: Oxford University Press, 1979, p. 65-86.

VIEIRA FILHO, J. E. R.; SILVEIRA, J. M. F. Modelo evolucionário de aprendizagem agrícola. Revista Brasileira de Inovação, v. 10, n. 2, p. 265-299, 2011.

WINTER, S. Schumpeterian competition in alternative technological regimes. Journal of Economic Behavior and Organization, v. 5, p. 287-320, 1984.

ENDEREÇOS PARA CORRESPONDENCIA

Evaldo Henrique da Silva - ehsilva@ufv.br

Departamento de Economia - Universidade Federal de Viçosa

Av. Ph. Rolfs, Sn - Campus Universitário

36571-000 - Viçosa (MG), Brasil

Lia Hasenclever - lia@ie.ufr..br

Instituto de Economia - Universidade Federal do Rio de Janeiro

Av. Pauster, n. 250, Urca

22290-240 - Rio de Janeiro (RJ), Brasil 
